\title{
Avoiding Liver Injury with Papaverine and Ascorbic Acid Due to Infrarenal Cross-Clamping: an Experimental Study
}

Serhat Huseyin'; Orkut Guclu'; Volkan Yüksel'; Gulen Sezer Alptekin Erkul', MD; Nuray Can²; Fatma Nesrin Turan³; Suat Canbaz ${ }^{1}$

\section{Abstract}

Objective: Ischemia-reperfusion injury after acute ischemia treatment is a serious condition with high mortality and morbidity. Ischemia-reperfusion injury may result in organ failure particularly in kidney, lung, liver, and heart. In our study, we investigated the effects of papaverine and vitamin C on ischemia-reperfusion injury developed in the rat liver after occlusion-reperfusion of rat aorta.

Methods: 32 Sprague-Dawley female rats were randomized into four groups $(n=8)$. Ischemia was induced with infrarenal aortic cross-clamping for 60 minutes; then the clamp was removed and reperfusion was allowed for 120 minutes. While the control group and the ischemia-reperfusion group did not receive any supplementary agent, two other groups received vitamin C and papaverine hydrochloride (papaverine $\mathrm{HCL}$ ). Liver tissues were evaluated under the light microscope. Histopathological examination was assessed by Suzuki's criteria and results were compared between groups.

Results: In ischemia-reperfusion group, severe congestion, severe cytoplasmic vacuolization, and parenchymal necrosis over $60 \%$ (score 4) were observed. In vitamin C group, mild congestion, mild cytoplasmic vacuolization and parenchymal necrosis below $30 \%$ (score 2) were found. In papaverine group, moderate congestion, moderate cytoplasmic vacuolization and parenchymal necrosis below $60 \%$ (score 3 ) were observed.

Conclusion: An ischemia of 60 minutes induced on lower extremities causes damaging effects on hepatic tissue. Vitamin C and papaverine are helpful in reducing liver injury after acute ischemia reperfusion and may partially avoid related negative conditions.

Keywords: Reperfusion Injury. Liver Diseases. Papaverine. Ascorbic Acid. Rats. Models, Animal.

\section{Abbreviations, acronyms \& symbols \\ I-R = Ischemia-reperfusion \\ Papaverine $\mathrm{HCL}$ = Papaverine hydrochloride}

\section{INTRODUCTION}

Ischemia develops during aortic surgery due to aortic clamping in lower extremities and the following reperfusion process brings about a systemic inflammatory response that causes endothelial injury and increasing vascular permeability. Non-cardiac pulmonary dysfunction can be indicated in many patients following an elective aorta surgery and is an important cause of postoperative morbidity ${ }^{[1]}$. During reperfusion, many

\footnotetext{
'Department of Cardiovascular Surgery of Trakya University School of Medicine, Edirne, Turkey.

Department of Medical Pathology of Trakya University School of Medicine,

Edirne, Turkey.

${ }^{3}$ Department of Biostatistics of Trakya University School of Medicine, Edirne, Turkey.

This study was carried out at the Trakya University School of Medicine, Edirne, Turkey.
}

chemical mediators are released into systemic circulation due to washout effect and contribute to distal organ injuries by organ capillary occlusions through possible microembolies ${ }^{[2-4]}$. Those result with increased permeability, platelet aggregation and necrotic areas due to microvascular endothelial injury in major organs ${ }^{[5]}$. This condition caused pulmonary edema and microproteinuria in the kidney. On the other hand, the effects of distal organ ischemia-reperfusion (I-R) injury on liver are examined in a limited number of studies.

Many treatment strategies have been developed to prevent and to reduce I-R injury. As vitamin C (ascorbic acid) has long been known for its antioxidant effect and papaverine has vasodilator effects, we assume that vitamin C and papaverine could reverse the vasoconstrictive effects of the chemical mediators released during systemic inflammatory response and may reduce I-R injury in hepatic tissue ${ }^{[6,7]}$.

\section{No conflict of interest.}

Correspondence Address:

Serhat Huseyin

Trakya University School of Medicine

Department of Cardiovascular Surgery

22030, Edirne, Turkey

E-mail: serhathuseyin@hotmail.com 
The aim of the present study is to perform a histopathological examination of the effects of vitamin $C$ and papaverine on liver tissues following I-R injury in lower extremities.

\section{METHODS}

\section{Study Design}

The study was performed in Experimental Animals Laboratory after the approval by Local Ethic Committee was obtained (Number: 36/2012). Thirty-two female Sprague-Dawley rats, 3.5-4 months old and weighing about 190-250 g, were used. The animals were randomly divided into four groups $(n=8)$. This experimental study was carried out in accordance with Animals Act and associated guidelines. All animals were handled in accordance with the Guide for the Care and Use of Laboratory Animals.

\section{Preparation of the animals and the surgical techniques}

All animals were given ketamin $\mathrm{HCl} 40 \mathrm{mg} / \mathrm{kg}\left(\mathrm{Ketalar}^{\circledR} 50\right.$ $\mathrm{mg} / \mathrm{ml}$ vial, Pfizer Drug Company, Istanbul, Turkey) + xylazine hydrochloride $5 \mathrm{mg} / \mathrm{kg}$ (Rompun ${ }^{\circledR} 23.32 \mathrm{mg} / \mathrm{ml}, 50 \mathrm{ml}$ vial, Bayer Drug Company, Istanbul, Turkey) after 8 hours fasting, with intramuscular anesthesia into left foot muscle, ensuring spontaneous respiration during the procedure. The animals were placed in a supine position on the table under a radiant heater. After the area of the skin aseptically prepared, all animals were subjected to median laparotomy from right below the xiphoid to $0.5 \mathrm{~cm}$ above pubis; intestines were deviated to the right side, then the infrarenal abdominal aorta and liver were explored through a blunt dissection. All animals were given a low dose (100 unites $/ \mathrm{kg}$ ) of heparin (Nevparin ${ }^{\circledR} 25000 \mathrm{IU} 5 \mathrm{ml}$ flakon, Mustafa Nevzat Drug Company, Istanbul, Turkey). Fluid resuscitation was supplied with $10 \mathrm{ml} / \mathrm{kg} 0.9 \% \mathrm{NaCl}$ through the tail vein. Infrarenal abdominal aorta was clamped with an atraumatic microvascular clamp (Novaclip 12 mm Angle, Plymouth, USA). After clamping, $5 \mathrm{ml}$ warm saline solution was injected into the peritoneal cavity. To prevent abdominal fluid loss, the skin area was approximated with a suture. After 60 minutes of ischemia, clamp was removed and we waited 2 hours for reperfusion. Ischemia was monitored by loss of pulsation in aorta and reperfusion was monitored by the presence of pulsation in aorta. The animals were sacrificed after the procedure, and the livers of all animals were removed and conserved in 10\% formalin.

\section{Experimental Groups}

Control Group (Group 1) (n=8)

Rats hepatectomised at the end of the targeted period without any other procedure following anesthesia and median laparotomy.

\section{Ischemia-Reperfusion Group (Group 2) (n=8)}

Rats hepatectomised at the end of the targeted ischemiareperfusion duration with induced ischemia-reperfusion following a standard surgical procedure.
Ischemia-Reperfusion + Vitamin C group (Group 3) (n=8)

Rats with induced ischemia following a standard surgical procedure, started infusion with $50 \mathrm{mg} / \mathrm{kg}$ dose of vitamin C (ascorbic acid) (Redoxan ${ }^{\circledR} 500 \mathrm{mg} / 5 \mathrm{ml}$ vial, Bayer Drug Company, Istanbul, Turkey) 15 minutes before declamping and hepatectomised at the end of the reperfusion duration.

Ischemia-Reperfusion + Papaverine Group (Group 4) (n=8)

Rats with induced ischemia following a standard surgical procedure, and started infusion with $1.5 \mathrm{mg} / \mathrm{kg}$ dose of papaverine $\mathrm{HCl}$ (Papaverin $\mathrm{HCl}^{\circledast} 0.05 \mathrm{~g} / 2 \mathrm{ml}$, Galen Drug Company, Istanbul, Turkey) 15 minutes before declamping, and hepatectomised at the end of the reperfusion duration.

\section{Histopathological Examination}

Liver tissues were fixed separately in 10\% buffered neutral formalin, and tissue monitoring was performed. From the samples, paraffin blocks were prepared and 4-5 $\mu \mathrm{m}$ sections were cut and stained with hematoxylin and eosin $(\mathrm{H}+\mathrm{E})$. Histopathological examinations were performed under a light microscope. Sinusoidal congestion, hepatocyte cytoplasm vacuolization and parenchymal necrosis were assessed as described by Suzuki et al. ${ }^{[8]}$ and scored on a scale from 0 to 4 (Table 1).

\section{Statistical Analysis}

Statistical evaluations were performed using Statistical Package for the Social Sciences 20 (SPSS Inc, Chicago, IL, USA) and, for multiple comparisons, Kruskal Wallis analysis of variance and Bonferroni corrected Mann-Whitney $U$ test were used. Descriptive statistics were median (min-max) values. Level of significance was accepted as $P \leq 0.05$; two-way and $P \leq 0.008$ for Bonferroni correction.

\section{RESULTS}

In our study, we used Suzuki classification in assessments and while no pathological differences were observed in the livers of three animals (Suzuki score 0), minimal congestion, minimal cytoplasmic vacuolization, and single-cell necrosis were observed in five animals (Suzuki score 1) in Group 1 (Figures 1A and B).

Table 1. Suzuki scoring scale.

\begin{tabular}{c|c|c|c}
\hline Score & Congestion & $\begin{array}{c}\text { Cytoplasmic } \\
\text { vacuolization }\end{array}$ & $\begin{array}{c}\text { Parenchymal } \\
\text { necrosis }\end{array}$ \\
\hline 0 & No & No & No \\
\hline 1 & Minimal & Minimal & $\begin{array}{c}\text { Single-cell } \\
\text { necrosis }\end{array}$ \\
\hline 2 & Mild & Mild & $<30 \%$ \\
\hline 3 & Moderate & Moderate & $<60 \%$ \\
\hline 4 & Severe & Severe & $>60 \%$ \\
\hline
\end{tabular}


।
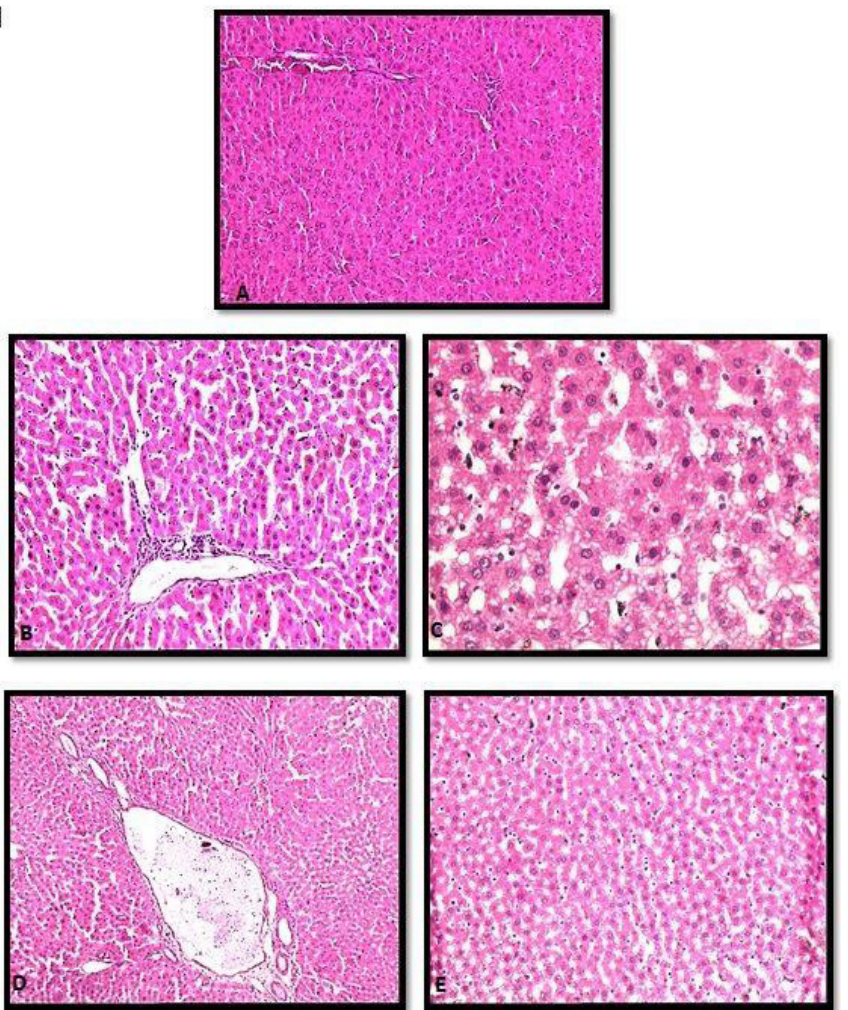

Fig. 1 - A) Group 1 subject 1, score 0: regular hepatic histology. B) Group 1 subject 8, score 1: sinusoidal congestion findings. C) Group 2 subject 6, score 4: marked congestion, extensive cytoplasmic vacuolization, focal cellular necrosis. D) Group 4 subject 5, score 2: sinusoidal congestion, mild level of cytoplasmic vacuolization. E) Group 4 subject 6. score 3: moderate level of congestion and cytoplasmic vacuolization.

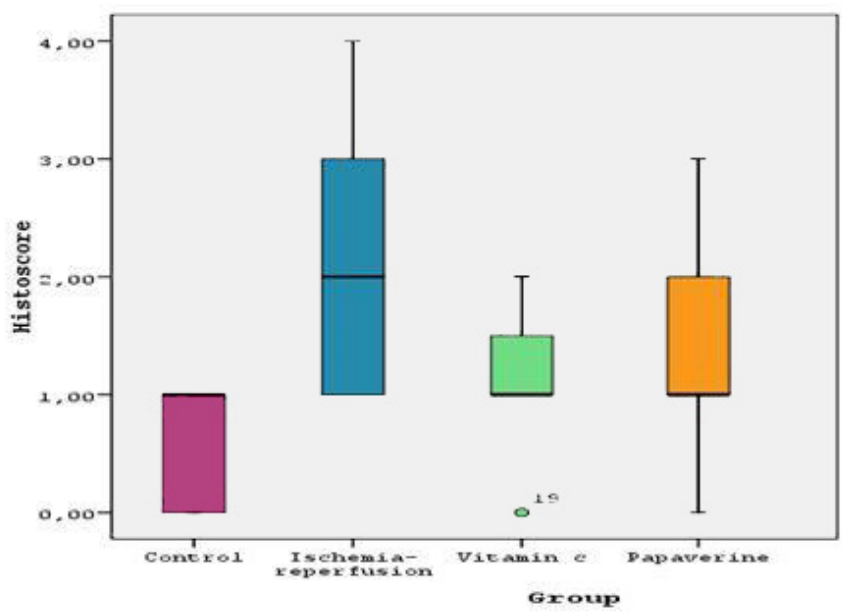

Fig. 2 - Histopathological scores by groups.

In Group 2, minimal congestion, minimal cytoplasmic vacuolization, and single-cell necrosis were observed in three rats (Suzuki score 1); mild congestion, mild cytoplasmic vacuolization and parenchymal necrosis below $30 \%$ were observed in two rats
Table 2. Histopathological scores by groups.

\begin{tabular}{l|c|c|c}
\hline Group & Median & Minimum & Maximum \\
\hline Control $(n=8)$ & 10.000 & 0 & 1.00 \\
\hline $\begin{array}{l}\text { Ischemia- } \\
\text { reperfusion ( } n=8)\end{array}$ & 20.000 & 1.00 & 4.00 \\
\hline \begin{tabular}{l} 
I-R +Vit C ( $n=8)$ \\
\hline $\begin{array}{l}\text { I-R+Papaverine } \\
(n=8)\end{array}$
\end{tabular} & 10.000 & 0 & 2.00 \\
\hline
\end{tabular}

(Suzuki score 2); moderate congestion, moderate cytoplasmic vacuolization, and parenchymal necrosis below 60\% were observed in two rats (Suzuki score 3); severe congestion, severe cytoplasmic vacuolization, and parenchymal necrosis above 60\% were observed in one rat (Suzuki score 4) (Figure 1C).

In Group 3, while no histopathological difference in the liver (Suzuki score 0) was observed in one animal, there were minimal congestion, minimal cytoplasmic vacuolization, and single-cell necrosis (Score 1) in five animals, and mild congestion, mild cytoplasmic vacuolization and parenchymal necrosis below 30\% (score 2) in two animals (Figure 1D).

In Group 4, although the histopathological examination of the liver revealed no difference (score 0 ), minimal congestion, minimal cytoplasmic vacuolization, and single-cell necrosis were observed in four animals (Score 1); mild congestion, mild cytoplasmic vacuolization, and parenchymal necrosis below 30\% were observed in two animals (Score 2); and moderate congestion, moderate cytoplasmic vacuolization and parenchymal necrosis below 60\% were observed (Score 3) in one animal (Figure 1E).

There was a statistically significant difference among the groups Suzuki scores $(P=0.021)$. In pairwise comparisons, while a significant difference ( $P=0.007)$ between Group 1 and Group 2 was found, the comparisons among other groups did not reveal any significant difference (respectively; Group 1 with Group 3, and with Group 4; $P=0.195 ; 0.105$; Group 2 with Groups 3 and 4; $P=0.083,0.234$; with Group 2 and Group 3; $P=0.645$ ). In other words, although similar histopathological values were obtained in the comparison of Groups 3 and 4 with Group 1 and of Group 3 with Group 4, the histopathological scores were lower in Group 1 in comparison to Group 2 ( $P=0.007$ ) (Table 2, Figure 2).

\section{DISCUSSION}

Infrarenal abdominal aortic surgery for abdominal aortic aneurysm and peripheric bypass surgery have remained the gold standard treatment despite the decreasing number of such procedure with the development of endovascular techniques ${ }^{[9]}$. I-R experiments constitute the experimental models simulating injuries developed following such organ surgeries, circulation shocks, and disseminated intravascular coagulation disorders ${ }^{[10]}$. Aortic clamping procedure used in abdominal aortic surgery is not an innocent procedure, as it is well known. Not only its local effects, but also the systemic effects contribute to this fact. In 
patients with peripheral arterial disease, who have abnormal microvascular perfusion, oxygen increase during reperfusion is higher and therefore, ischemic injury is more severe ${ }^{[10]}$. For this reason, antioxidant agents to reduce the injury are being tested in experimental models which otherwise require a long processes to clinical application ${ }^{[10]}$.

In this study, we used ascorbic acid, because it is the strongest antioxidant soluble in water. We also used papaverine, an opium alkaloid and a good vasodilator that is thought to have an antioxidant effect through inhibition of mitochondrial glutamate oxidase system for decreasing oxidative stress and lipid peroxidation ${ }^{[10,11-13]}$. We found that ascorbic acid and papaverine caused some decrease in I-R related histopathological injury, although not reaching a statistically significant level. Various studies have addressed the use of similar agents in similar durations and their beneficial effects. In experimental studies on rats, reperfusion of distal organ ischemia has been shown to cause injury in lungs, kidneys, and in small intestine, and the use of certain molecules, such as melatonin, oxytocin, ascorbic acid and complement inhibitors, has reductive effects on the injuries ${ }^{[14-22]}$. Strategies directed at reducing apoptosis are thought to improve survival after ischemia and reduce reperfusion injury ${ }^{[8,23]}$.

We need to look at the pathophysiological process, caused by the condition in lower limbs. Skeletal muscle of the lower limbs is the major tissue that is susceptible to ischemia. Irreversible muscle injury starts after 3 hours of ischemia and complete at the $6^{\text {th }}$ hour [24]. Mortality and amputation rates in acute peripheric arterial occlusion have been reported as $10-25 \%$ and $20 \%$, respectively. Duration of ischemia has great importance among the factors that affect mortality and morbidity ${ }^{[25]}$. Free oxygen radicals, TNF-alpha and other mediators released into circulation during I-R activate various proteins involved in apoptosis. This causes DNA damage and cell death ${ }^{[14,15,23]}$. The more affected tissue mass and duration of ischemia, the more severe are the complications ${ }^{[24]}$.

The effects ofl-Rinjury occur after 45 minutes in lungs and after 60 minutes of ischemia in extremities during reperfusion ${ }^{[15,26,27]}$. The tolerable duration of normothermic hepatic ischemia is not known and thought that irreversible injury occurs after 90 minutes of elective liver surgery ${ }^{[18]}$. However, there is a limited number of clinical and experimental studies on distal organ I-R-related liver injury. In literature, there two studies that have reported the histopathological and biochemical effects of distal organ ischemia reperfusion on liver ${ }^{[17]}$. Based on similar studies, we planned to use I-R duration as 60 minutes of ischemia and 120 minutes of reperfusion ${ }^{[14,16]}$. We also demonstrated in our study that 60 minutes of ischemia and 120 minutes of reperfusion induced in lower limbs of healthy subjects caused a significant I-R injury in hepatic tissue histopathologically.

However, clinical studies have shown that the liver injury occurred in this part is influenced by many other factors, from hepatic lipid content to various systemic factors like acute hyperglycemia ${ }^{[8,23]}$. Sprung et al.[28], in their clinical study on 942 consecutive patients who had elective abdominal aortic aneurysm and vasculopathy, found an acute increase in hepatic enzymes in $1.5 \%$ of the patients at 24-72 hours postoperatively. However, we did not analyze the effects of the systemic factors on our subjects due to limited technical resources. This is a limitation in our study. Another limitation is that the subjects in our study do not have any vasculopathy and systemic risk factors, unlike real patient population.

Initiation time of the antioxidant agents is also important. Since the free radicals formation has shown to occur rapidly (in the first seconds of the reperfusion), it has been known that the use of free radical scavengers is only effective when it is initiated 15 minutes prior to reperfusion if it is to reduce the reperfusion injury, and it has not any protective effect when initiated after reperfusion ${ }^{[2,29]}$. In our study, distal ischemia was also induced and at 45 minutes of ischemia, that is, 15 minutes before reperfusion antioxidant agent was initiated and the histopathological results were analyzed by using Suzuki classification ${ }^{[16]}$. Although similar histopathological values were obtained in the comparison of Group 3 and Group 4 with Group 1 and Group 3 with Group 4, the histopathological scores were lower in the control group in comparison with Group 2. In other words, Group 4 and Group 3 revealed similar results, yet the level of injury in these groups were lower compared to Group 2, although not statistically significant. In addition, Andrews et al. ${ }^{[30]}$ demonstrated that, in experimental ischemia model in the gastric mucosa before reperfusion, the use of agents that increase gastric blood flow and vasodilator papaverine do not have any beneficial effect on I-R injury. These findings suggest that papaverine may have different effects depending on the type of ischemia, or on the organ involved. In another study, Koçarslan et al. ${ }^{[31]}$ showed that intraperitoneal administration of silymarin reduces oxidative stress and protects liver, kidney, and lungs from acute supraceliac abdominal aorta ischemia-reperfusion injury in the rat model. Pharmacological, genetic and surgical studies directed at decreasing I-R injury would elucidate the prospect to decrease mortality and morbidity caused by vascular diseases and surgeries.

\section{CONCLUSION}

In conclusion, we revealed that an ischemia of 60 minutes induced on lower limbs is sufficient to cause damaging effects on hepatic tissue. We conclude that both papaverine and ascorbic acid, given 15 minutes prior to reperfusion, reduced hepatic injury caused by reperfusion following ischemia in lower limbs in experimental conditions.

\section{Authors' roles \& responsibilities}

SH Conception and design study; conduct of procedures and/ or experiments; writing of the manuscript or review of its content; final manuscript approval

OG Analysis and/or data interpretation; final manuscript approval

VY Manuscript redaction or critical review of its content; final manuscript approval

GSAE Analysis and/or data interpretation; final manuscript approval

NC Pathological examination; final manuscript approval

FNT Statistical analysis; final manuscript approval

SC Critical review of its content; final manuscript approval 


\section{REFERENCES}

1. Smith FC, Gosling P, Sanghera K, Green MA, Paterson IS, Shearman CP. Microproteinuria predicts the severity of systemic effects of reperfusion injury following infrarenal aortic aneurysm surgery. Ann Vasc Surg. 1994;8(1):1-5.

2. Colletti LM, Kunkel SL, Walz A, Burdick MD, Kunkel RG, Wilke CA, et al. Chemokine expression during hepatic ischemia/reperfusion-induced lung injury in the rat. The role of epithelial neutrophil activating protein. J Clin Invest. 1995;95(1):134-41.

3. Goksin I, Akbulut M, Baltalarli A, Sacar M, Kaya S, Ozcan V, et al. The effect of normovolemic hemodilution on lung injury after ischemiareperfusion of lower extremities. Turkish J Thorac Cardiovasc Surg. 2006;14(1):54-8.

4. Sirin H, Saribulbul O, Cerrahoglu M, Aksoy O, Baltalarli A, Sacar M, et al. Protective effect of aprotinin on lung injury caused by ischemiareperfusion of the lower extremities. Turkish JThorac Cardiovasc Surg. 2001;9:233-7.

5. Saba D, Yavuz H, Senkaya I, Agris M, Ozer Z, Ozkan H, et al. The effects of calcium dobesilate on skeletal muscle ischemia. Turkish J Thorac Cardiovasc Surg. 2000;8:797-801.

6. Serracino-Inglott F, Habib NA, Mathie RT. Hepatic ischemia-reperfusion injury. Am J Surg. 2001;181(2):160-6.

7. Montalvo-Jave EE, Escalante-Tattersfield T, Ortega-Salgado JA, Piña $\mathrm{E}$, Geller DA. Factors in the pathophysiology of the liver ischemiareperfusion injury. J Surg Res. 2008;147(1):153-9.

8. Suzuki S, Nakamura S, Koizumi T, Sakaguchi S, Baba S, Muro H, et al. The beneficial effect of a prostaglandin 12 analog on ischemic rat liver. Transplantation. 1991;52(6):979-83.

9. Yavuz S, Ozbudak E, Gumusta S, Kanko M, Ciftci E, Berki T. Endovascular stent-graft applications in abdominal aortic aneurysms: mid- and long-term results. Turkish J Thorac Cardiovasc Surg. 2013;21:333-40.

10. Adingupu DD, Thorn CE, Casanova F, Elyas S, Gooding K, Gilchrist M, et al. Blood oxygen saturation after ischemia is altered with abnormal microvascular reperfusion. Microcirculation. 2015;22(4):294-305.

11. Salman E, Bayraktaroglu M, Dogan OV, YorukogluY, Yucel E, Kosebalaban $\mathrm{S}$, et al. Use of ascorbic acid in open heart surgery as an oxygen free radical scavenger. Turkish J Thorac Cardiovasc Surg. 1994;2:216-20.

12. Chandra R, Aneja R, Rewal C, Konduri R, Dass SK, Agarwal S. An opium alkaloid-papaverine ameliorates ethanol-induced hepatotoxicity: diminution of oxidative stress. Indian J Clin Biochem. 2000;15(2):155-60.

13. Urakov AL, Baranov AG. Effect of papaverine on the energy processes of myocardial mitochondria. Farmakol Toksikol. 1979;42(2):132-6.

14. Uysal A, Burma O, Akar I, Ozsin KK, Rahman A, Ustundag B, et al. Protective effect of melatonin on lung injury caused by ischemia-reperfusion of the lower extremities. Turkish JThorac Cardiovasc Surg. 2006;14:308-14.

15. Isbir S, Akgun S, Ak K, Civelek A, Tekeli A, Cobanoglu A, al. Effect of acute lower limb ischemia / reperfusion injury on the free oxygen radical systems in lungs. Turkish JThorac Cardiovasc Surg. 2000;8:632-4.
16. Kaçmaz A, User EY, Sehirli AO, Tilki M, Ozkan S, Sener G. Protective effect of melatonin against ischemia/reperfusion-induced oxidative remote organ injury in the rat. Surg Today. 2005;35(9):744-50.

17. Oktar GL, Demir Amac N, Elmas C, Arslan M, Goktas G, Iriz E, et al. The histopathological effects of levosimendan on liver injury induced by myocardial ischemia and reperfusion. Bratisl Lek Listy. 2015;116(4):241-7.

18. Tas Hekimoglu A, Toprak G, Akkoc H, Evliyaoglu O, Ozekinci S, Kelle I. Oxytocin ameliorates remote liver injury induced by renal ischemiareperfusion in rats. Korean J Physiol Pharmacol. 2013;17(2):169-73.

19. Smith FC, Gosling P, Sanghera K, Green MA, Paterson IS, Shearman CP. Microproteinuria predicts the severity of systemic effects of reperfusion injury following infrarenal aortic aneurysm surgery. Ann Vasc Surg. 1994;8(1):1-5.

20. Takhtfooladi H, Takhtfooladi M, Moayer F, Mobarakeh S. Melatonin attenuates lung injury in a hind limb ischemia-reperfusion rat model. Rev Port Pneumol. 2015;21(1):30-5.

21. Yassin MM, Barros D'Sa AA, Parks G, Abdulkadir AS, Halliday I, Rowlands BJ. Mortality following lower limb ischemia-reperfusion: a systemic inflammatory response? World J Surg. 1996;20(8):961-6.

22. Berkan O, Yıldız E, Katrancıoglu N, Gunay I. Effect of ascorbic acid in the lung injury caused by ischemia reperfusion of the lower extremities. Turkish J Thorac Cardiovasc Surg. 2001;9:238-41.

23. Montalvo-Jave EE, Escalante-Tattersfield T, Ortega-Salgado JA, Piña E, Geller DA. Factors in the pathophysiology of the liver ischemiareperfusion injury. J Surg Res. 2008;147(1):153-9.

24. Blaisdell FW. The pathophysiology of skeletal muscle ischemia and the reperfusion syndrome: a review. Cardiovasc Surg. 2002;10(6):620-30.

25. Güler A, Sahin MA, Karabacak K, Küçükaslan N, Yokusoglu M, Tatar H. Accompanying embolectomy and closed fasciotomy in the same session for the delayed arterial thromboembolic occlusions in lower extremity. Anadolu Kardiyol Derg. 2009;9(5):407-10.

26. Paller MS, Hoidal JR, Ferris TF. Oxygen free radicals in ischemic acute renal failure in the rat. J Clin Invest. 1984;74(4):1156-64.

27. Dosluoglu HH, Aktan AO, Yegen C, Okboy N, Yalçm AS, Yahn R, et al. The cytoprotective effects of verapamil and iloprost (ZK 36374) on ischemia/reperfusion injury of kidneys. Transpl Int. 1993;6(3):138-42.

28. Sprung J, Levy PJ, Tabares AH, Gottlieb A, Schoenwald PK, Olin JW. Ischemic liver dysfunction after elective repair of infrarenal aortic aneurysm: incidence and outcome. J Cardiothorac Vasc Anesth. 1998;12(5):507-11.

29. Park JL, Lucchesi BR. Mechanisms of myocardial reperfusion injury. Ann Thorac Surg. 1999;68(5):1905-12.

30. Andrews FJ, Malcontenti-Wilson C, O'Brien PE. Protection against gastric ischemia-reperfusion injury by nitric oxide generators. Dig Dis Sci. 1994;39(2):366-73.

31. Koçarslan A, Koçarslan S, Aydin MS, Gunay S, Karahan MA, Taskin A, et al. Intraperitoneal administration of silymarin protects end organs from multivisceral ischemia/reperfusion injury in a rat model. Braz J Cardiovasc Surg. 2016;31(6):434-9. 